\title{
EXPLORING USERS' ATTITUDES AND INTENTIONS TOWARD THE ADOPTION OF CLOUD COMPUTING IN SAUDI ARABIA: AN EMPIRICAL INVESTIGATION
}

\author{
Mutlaq B. Alotaibi \\ Al Imam Mohammad Ibn Saud Islamic University (IMSIU), Saudi Arabia
}

Received 2014-06-19; Revised 2014-06-29; Accepted 2014-11-29

\begin{abstract}
Over the past few years, cloud computing has evolved as one of the major advances in the field of Information Technology (IT) utilizing third-party services. Therefore, trust in cloud vendors as well as the determination of potential risks, such as privacy and security issues, are crucial for ensuring the successful adoption of an appropriate cloud. Prior research have addressed the technical aspects of cloud-based environments, such as cloud virtualization, scalability and security. Nevertheless, it is argued that the biggest obstacle of cloud computing is not technological, rather it is perceptual or attitudinal. The adoption of cloud computing has been central to several scholarly research areas, particularly user acceptance. This study presents an extended Technology Acceptance Model (TAM), which integrates Trust (TR), Anxiety (ANX) and Perceived Risk (PR), to investigate users' attitudes and intentions toward the adoption of cloud computing. The proposed model was empirically examined using the Structural Equation Model (SEM) to analyze data gathered by a survey of both IT professionals and end users. The results herein suggested that trust, anxiety and PR can be successfully integrated within the TAMs. Trust has demonstrated to have a strong positive influence on Perceived Ease of Use (PEOU), but it had no significant effects on Perceived Usefulness (PU). Both anxiety and PR were found to have significant negative effects on PEOU and PU. In addition, Behavioral Intention (BI) to use the cloud can be predicted by trust, attitudes and PU, as PR was shown to have no significant effect on BI. The proposed model, including PR, trust and anxiety, has been demonstrated to be a true predictor of user intentions, toward the use of cloud computing, within the context of Saudi Arabia.
\end{abstract}

\section{Keywords: Technology Acceptance, Cloud Computing, Structural Model, Trust, Perceived Risk, Saudi Arabia}

\section{INTRODUCTION}

Cloud computing represents a radically different computing paradigm that has altered the way in which Information Technology (IT) services and capabilities are delivered to consumers (Marston et al., 2011). Rapid technological progress has occurred within this corporate computing model; as a result, increases in capital investment are expected in this field. According to research conducted by Gartner, it is expected that investments in cloud computing will reach more than $\$ 150$ billion by 2014 (Marston et al., 2011). As a rapidly emerging IT trend, the cloud hype, which recently reached a peak in terms of its expectations, generally describes the user's perception of cloud computing (Buyya et al., 2009b). Despite the cloud hype, migration from internal data centers to clouds involves certain tradeoffs (Khajeh-Hosseini et al., 2010). On one hand, the migration offers several opportunities to manage income and outcomes while also improving management, satisfaction and organizational growth (Khajeh-Hosseini et al., 2010); conversely though, it presents a threat to the quality of customer care and support as well as potentials to the downsizing of IT departments. More importantly, cloud adoption 
involves outsourcing critical operations and migrating critical data and information to third-party infrastructures (Khajeh-Hosseini et al., 2010).

As cloud computing continues to utilize third-party services, trust in cloud vendors as well as the determination of potential risks, such as privacy and security issues, are crucial for ensuring the successful adoption of an appropriate cloud (Buyya et al., 2009a). A number of previous studies have addressed the technical aspects of cloud-based environments, such as cloud virtualization, scalability and security (Bogataj and Pucihar, 2012). Nevertheless, it is argued that the biggest obstacle of cloud computing is not technological, rather it is perceptual or attitudinal (Marston et al., 2011). Therefore, this study aims to investigate users' attitudes and perceptions toward cloud computing environments, with a particular focus on the perception of risk, trust and anxiety, in order to explore the factors affecting the acceptance of cloud technology and services in Saudi Arabia. These factors will be examined using a proposed conceptual model that is based on the Technology Acceptance Model (TAM) whereby the following three variables of trust, anxiety and perceived risk will be incorporated. The scope of this study will cover the attitudes and intentions towards cloud computing, including trust and the context of this investigation will include the perceptions of IT professionals and end-users.

A great deal of research has identified and predicted increases in the importance of trust, anxiety and perceived risk in cloud computing environments, however only a few studies have examined the effect of these factors on cloud computing adoption behaviors. The aim of this study is to understand the adoption behavior of cloud computing, particularly users' acceptance of cloud technology and its services. This study will contribute to the current literature by explaining the role of trust, perceived risk and computer anxiety in the adoption behavior of cloud computing. It will also confirm whether the TAM is a valid model based on the way in which users' attitudes and intentions can be explained in the context of cloud computing.

This study will be structured as follows: The next section will discuss any relevant prior research and the theoretical background in order to present the way in which cloud computing and the TAM emerged and have developed. The third section will present the development research hypotheses and the fourth section will describe this empirical study by identifying the research method, sample characteristics, reliability and validity of the research intrument and the model testing results. The fifth section will present a discussion which will include implications of the results, limitations and suggestions for further research and, finally, the sixth section will provide conclusions.

\section{PRIOR RESEARCH AND THEORETICAL BACKGROUND}

\subsection{Cloud Computing}

The concept of cloud computing reflects the convergent evolution of two emerging and key business trends: IT efficiency and business agility (Marston et al., 2011). The former refers to the utilization of computing resources in an efficient and scalable manner, whereas the latter denotes the use of IT as a competitive advantage to respond quickly to market changes in order to ensure rapid development and enterprise mobility. Technically speaking, cloud computing is an IT service delivery model that offers hardware and software services to IT consumers in a self-service (on-demand), per-usage billing capacity (employs a metering system) which is elastic (rapidly provisioned), customizable and ubiquitous in its manner (Fox et al., 2009). Based on the service model of the cloud vendors and the level of abstraction, cloud computing services can be categorized into the following three main layers (Youseff et al., 2008). First, the Infrastructure as a Service (IaaS) layer offers an on-demand virtualization of IT resources, such as storage, communications and computing (Sotomayor et al., 2009). Secondly, the Platform as a Service (PaaS) layer provides a scalable cloud-based software development and deployment environment (Youseff et al., 2008). Thirdly, the Software as a Service (SaaS) layer delivers online software services, such as traditional desktop-based applications that are offered as a service on the web (Mohana and Thangaraj, 2013). Irrespective of the cloud computing service type, the cloud deployment models are categorized as either public or private clouds (Sotomayor et al., 2009). The former denotes a cloud service which is offered to the public in a pay-per-usage manner, while the latter is regarded as a data center that internally serves a particular organization and as such is not available to the public (Sotomayor et al., 2009). Some cloud environments are described as being hybrids as they are considered to be similar to the private cloud, but they can be supplemented by computing capabilities that can be leased from public clouds in order to cope with sudden spikes in load (Sotomayor et al., 2009).

Cloud computing offers several advantages for businesses, including cost reduction, energy savings, increased speed to markets, service scalability and other 
technical benefits. Basically, cloud computing offers large amounts of computing power and storage for relatively small budgets and at lower energy consumptions (Buyya et al., 2009b). In addition to saving energy and reducing costs, cloud computing can also help organizations to reap the benefits of the use of IT without the need for upfront investment (Buyya et al., 2009b). In the cloud computing model, IT costs are unusually treated as operational expenses thus helping to reduce upfront costs and improve the time to market. Furthermore, managers can focus more on their business models by scaling services up or down in line with business requirement changes, because computing resources are fully managed with minimal consumer interaction (Buyya et al., 2009b). Technically speaking, cloud computing can efficiently handle spikes in demand by the virtualization of computer resources (Aymerich et al., 2008). In addition, cloud computing can provide instant and continual access to stored data, anytime and anywhere, through the use of mobile devices by the virtualization of storage resources (Aymerich et al., 2008). In summary, cloud computing offers several technical and economic benefits.

Despite the reputation and potential of cloud computing, this promising model of computing is still facing several challenges. Firstly, it is challenging for cloud computing to offer secure services for IT environments that are equal to those found in in-house data centers (Fox et al., 2009). Secondly, the aspects of cloud computing exacerbate the privacy issues further, due to the massive involvement of third-party infrastructures and hosting services (Fox et al., 2009). Thirdly, the adoption of cloud computing raises legal and regulatory concerns pertaining to the physical location of hosted data as well as the determination of data management laws which need to be applied to data breach cases (Dillon et al., 2010). Fourthly, cloud computing requires interoperability and portability mechanisms that enable the end user to migrate from one provider to another (Dillon et al., 2010). Finally, the quality of cloud services needs to be set in advance through the use of Service Level Agreements (SLA) in order to guarantee reliability, availability and performance at the desired levels (Mehdi et al., 2011). In summary, there are several challenges which need to be fully addressed before cloud computing can become beneficial for all organizations and individuals.

In recent years, the adoption of cloud computing has become an area of increasing importance for IT research and practice (Marston et al., 2011). For example, one stream of research utilized different technology adoption models to understand the consumer's adoption behavior of cloud computing. For example, a study by Taylor and
Hunsinger (2011), on the attitudes and intensions of university students to use Google Docs, found that intentions to use cloud computing can be predicted by students' Attitudes Toward Cloud (ATC) technology and other constructs derived from the Theory of Planned Behavior (TPB). Another study by Coursaris et al. (2013) proposed a holistic model to the adoption behavior of cloud computing by incorporating contextual, demographic and lifestyle variables using the Diffusion of Innovations Theory (DIT). The study found that the adoption of cloud computing is influenced by innovation, expected benefits and compatibility (Coursaris et al., 2013).

Another stream of research, which focused on the implications of migrating to a cloud, addressed the switching behavior to a cloud environment and the cloud contribution to improving organizational efficiency. For example, using a two-factor theory, an empirical investigation by Park and Ryoo (2012) on the switching behavior, from the traditional way of IT adoption to cloud computing in Korea, found that user intentions to switch to cloud computing were positively influenced by the expected benefits and negatively influenced by the expected costs. Another study by Obeidat and Turgay (2012) extended the evaluation of cloud computing adoption, beyond the scope technology acceptance behavior, to cover multiple perspectives using the Triple$\mathrm{T}$ Model, they found that the advantages of cloud services outweighed its disadvantages. As such, this study provided empirical evidence that cloud computing adoption is beneficial to organizations as it contributes to improving overall enterprise performance.

\subsection{Technology Acceptance Model}

The TAM is considered to be one of the most established theories of technology adoption and it has been demonstrated to be highly predictive of the adoption of various IT systems (Lee et al., 2003). The TAM was originally proposed back in 1986 by (Davis, 1989), it later became commonly adopted into several theories of technology acceptance (Al-Gahtani, 2001; Al-Somali et al., 2009). The TAM was developed to predict users' acceptance of IT, which can be determined by two perceptual beliefs: Perceived Usefulness (PU) and Perceived Ease of Use (PEOU) (Davis, 1989). PU denotes the extent to which the user think that IT can contribute to the improvement of their job performance (Davis, 1989). PEOU, in contrast, is concerned with the simplicity of using a new technology which can be described as the extent to which the user thinks that their use of the new IT would be effortless (Davis, 1989). The TAM was extended from the Theory of Reasoned Actions (TRA) by (Fishbein and Ajzen, 1975). 


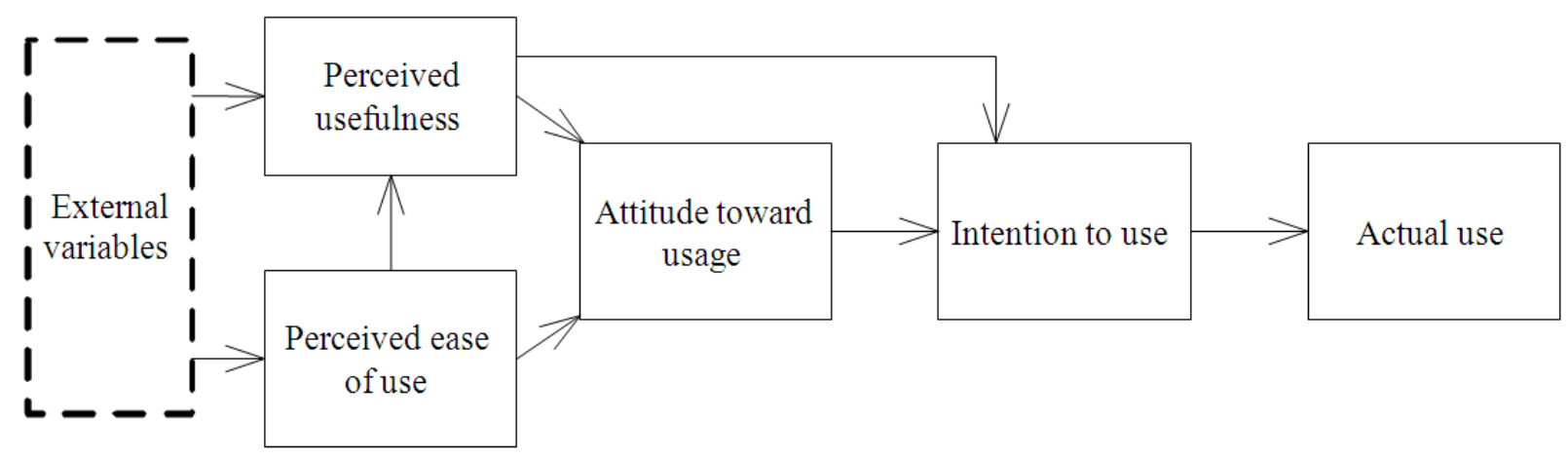

Fig. 1. The technology acceptance model (Adapted from (Davis, 1989))

The main components of the TAM are: PU and PEOU; this incorporates attitudes toward usage and behavioral intentions toward using new IT. Firstly, Barua et al. (1995) argued that when the user accepts the use of a particular technology, the usefulness of the specified technology is influenced by two factors: Cost and productivity. The cost contributes negatively to user attitudes toward technology, while the productivity contributes positively. Therefore, it can be said that PU has a positive influence on both the attitudes toward new technologies and behavioral intention to use that technology. This argument is supported by several empirical evidences that were found in TAM-based investigations (Atkinson and Kydd, 1997; Moon and Kim, 2001). Therefore, it can be said that PU is positively associated with the attitudes toward usage and behavioral intentions to use the new technology. Secondly, Davis (1989) argued that PEOU is positively associated with attitudes toward the new technology; this argument is supported by Barua et al. (1995) as lower complexity of the new technology is associated with lower costs and higher values. Furthermore, PEOU has been shown to have a positive influence on PU in several field studies, such as Email (Gefen and Straub, 1997), online banking (Liao et al., 1999) and online shopping (Gefen, 2004). Therefore, it can be said that PEOU has a positive influence on PU and attitudes toward using the new technology. Thirdly, attitudes toward usage have been shown to positively influence the behavioral intentions to use the new technology (Fishbein and Ajzen, 2011). Finally, it was also revealed that intentions toward the use of a new technology positively effects the actual usage of that technology (Pavlou and Chai, 2002; Venkatesh and Davis, 1996). The TAM can be seen above in Fig. 1, where the effect of external variables was theorized to be mediated by PU and PEOU (Venkatesh and Bala, 2008).

\section{HYPOTHESES DEVELOPMENT}

Although the TAM has been shown to have a predictive power, several researchers have also created context-specific constructs, such as E-Commerce, EMail (Venkatesh and Bala, 2008). Basically, there were three trends for the modifications of the TAM: Incorporating new external variables, modifying predictive factors and examining moderating effects (King and He, 2006). In the context of cloud computing, there was one stream of research that utilized extended versions of the TAM to examine user attitudes and intentions toward the cloud. For example, Opitz et al. (2012) investigated the adoption of cloud services and technologies by IT departments in Germany, using a modified TAM, they found that the acceptance of cloud services and technologies can be predicted by several factors derived from an extended version of the common TAM. Another study by (Alharbi, 2012) demonstrated that the TAM is a valid model for studying the acceptance of cloud computing in Saudi Arabia.

In the current paper, TAM was adapted to fit the context of cloud computing. In particular, the modification of the TAM involves incorporating new external variables that have been shown to have a potential effect on cloud computing adoption. In addition, the proposed model posits a crossover effect that the factors affecting PEOU will have similar effects on PU and vice-versa (Venkatesh and Bala, 2008). In general, in order to assess the acceptance of cloud computing, an analysis and understanding of the adoption behavior of cloud computing should occur (Nyoni and Piderit, 2012). In the context of TAM, several factors were proposed to predict the acceptance of cloud computing, these external variables were theorized to be mediated by PU and PEOU (Venkatesh and Bala, 2008). In particular, trust, anxiety and perceived risk were among 
the factors that could potentially affect cloud computing acceptance (Nyoni and Piderit, 2012; Wu, 2013; Wu et al., 2013). In addition, trust has shown to have positive relationships with both PU and PEOU in TAM contexts (Pavlou, 2003). Therefore, it can be said that trust is associated positively with PEOU and PU of cloud computing; to illustrate:

\section{H1: Trust will have a positive impact on perceived} usefulness of the cloud.

H2: Trust will have a positive impact on perceived ease of using the cloud.

The influence of general computing beliefs cannot be ignored, as the prior research suggested. For example, Venkatesh and Bala (2008) suggested that PEOU of any new technology is negatively affected by anchoring beliefs, like computer anxiety. In cloud computing environments, the effect of anxiety was also recognized in a recent study by $\mathrm{Wu}$ (2013), but this was included within the attitudes construct. Similarity, Udoh (2012) suggested that anxiety inhibits the adoption of cloud services and technologies, but anxiety was represented within antecedents of trust, as user apprehension about cloud security, privacy and reliability. In the current study, perceived risks and trust were considered as two different external variables that could affect PU and PEOU. Therefore, it is important to incorporate anxiety as a determinant of PEOU as an anchoring belief that is separated from both perceived risk and trust. As a crossover effect, it is hypothesized that determinants of PEOU will affect PU and vice-versa, anxiety was also proposed as a construct that negatively influences perceptual beliefs. Drawing upon this, it can be argued that computer anxiety is negatively associated with both PEOU and PU, in the context of cloud computing; to illustrate:

H3: Anxiety will have a negative impact on perceived usefulness of the cloud.

H4: Anxiety will have a negative impact on perceived ease of using the cloud.

Perceived risk indicated a combination of uncertainty and adverse consequences that usually affect the consumer's decision to adopt a certain technology (Dowling, 1986). Scholarly research in the E-Business field emphasized that brick and mortar business involves fewer risks, in comparison with online business (Drennan et al., 2006; Samadi and Nejadi, 2009). Having cloud computing defined as an internet-based service delivery environment, it raises privacy and security concerns (Albaroodi et al., 2014; Biswas and Biswas, 2004). Therefore, it can said that the decision to adopt cloud computing implies uncertain and risky situations. Therefore, it can be argued that perceived risks is negatively associated with both PEOU and PU, in the context of cloud computing; to illustrate:

H5: Perceived risk of the cloud will negatively influence perceived usefulness of the cloud.

H6: Perceived risk of the cloud will negatively influence perceived ease of using the cloud.

Within the main fundamentals of the TAM, it hypothesized that PEOU will have a significant effect on PU. In addition, both PEOU and PU were hypothesized to be predictors of attitudes toward the new technology. The following three hypotheses were taken from the original TAM, yet they were modified particularly for the current study, as the TAM model was adapted to fit the context at hand; to illustrate, three hypotheses were adapted from a recent study of cloud-specific TAM (Alharbi, 2012).

H7: Perceived usefulness of the cloud will positively influence attitudes toward the cloud.

H8: Perceived ease of use will positively influence perceived usefulness of the cloud.

H9: Perceived ease of use will positively influence attitudes toward the cloud.

In recent studies, both trust and attitudes, toward the cloud technology, have been demonstrated to be major precursors of BI to use the cloud. For example, an investigation by Udoh (2012), on the factors affecting the adoption of cloud technology using a modified TAM, found that attitudes and trust were explained respectively as 27 and $21 \%$ of the variance in BI. The following hypotheses were therefore developed:

\section{H10: Trust will positively influence behavioral intention} to use the cloud.

H12: Attitudes toward the cloud will have a positive impact on behavioral intention to use the cloud.

In addition, BI to use the cloud is positively associated with PU of the cloud (Alharbi, 2012). One of the hypotheses was adapted from a recent study of cloud-specific TAM (Alharbi, 2012)-this was derived from the original TAM. The following hypothesis was therefore developed:

H11: Perceived usefulness of the cloud will have a positive impact on behavioral intention to use the cloud. 


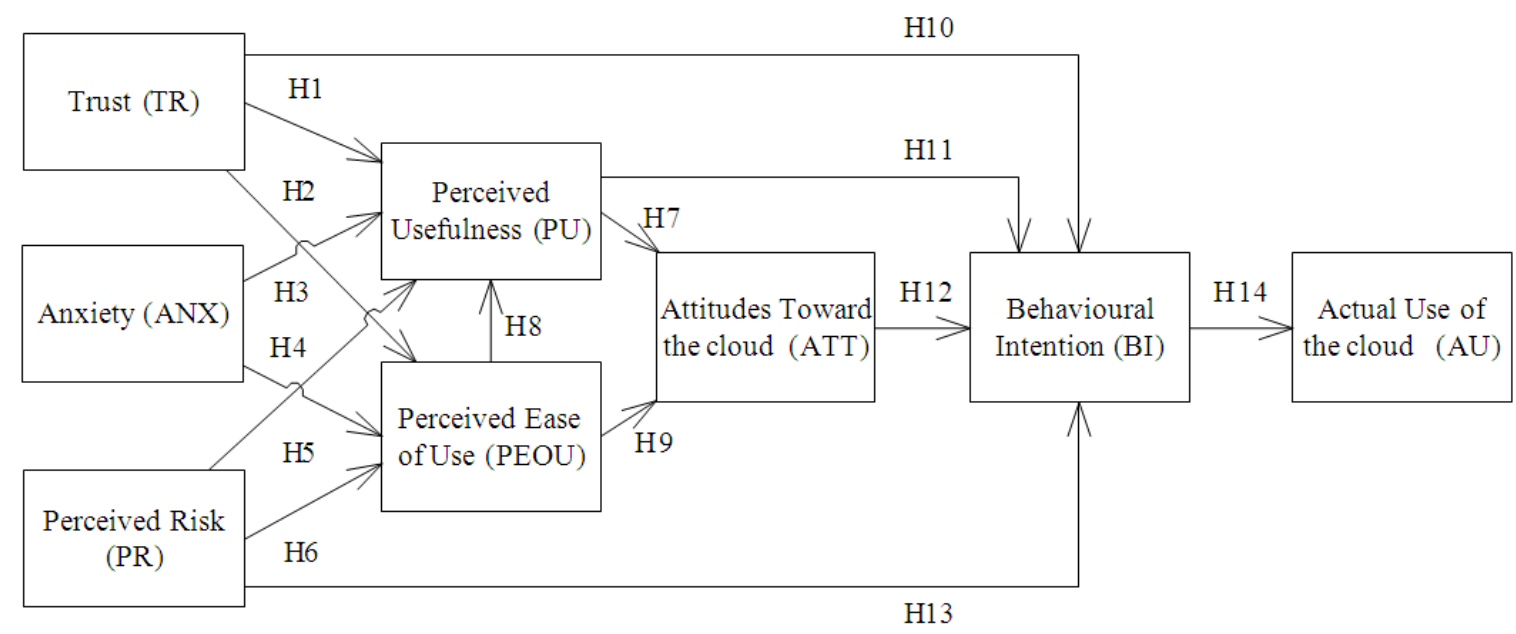

Fig. 2. Research model

In addition, BI to use the cloud was found to be negatively associated with perceived risk. For example, a recent study by (Chi et al., 2012), on the effect of perceived risk to behavioral intention to use cloud services and technologies, found that perceived risk by users is a key challenge which can hinder the adoption of cloud services and technologies. In particular, perceived risk was found to be negatively associated with behavioral intention to use cloud services; to illustrate:

\section{H13: Perceived risks will negatively influence behavioral intention to use the cloud.}

Finally, the actual use of cloud computing can be predicted only by the BI to use the cloud. Therefore, the last hypothesis was taken from a recent study of a cloudspecific model (Taylor and Hunsinger, 2011).

\section{H14: Behavioral intention will positively influence the actual use of the cloud.}

Based on these arguments, our study integrated the three additional variables of Trust (TR), Anxiety (ANX) and Perceived Risk (PR) into the TAM to determine user acceptance in the context of cloud computing. The main constructs of the TAM (PU, PEOU, BI, ATT and AU) were adapted to fit the context of cloud computing. The external variables were also incorporated into the model, as shown in Fig. 2; this included trust, anxiety and perceived risk. In addition, the study shows respondents' demographics by four control variables: Gender, background, age and education.

\section{EMPIRICAL STUDY}

This study follows a quantitative research design by using a survey methodology (Salkind and Rainwater, 2000) to examine the proposed hypotheses and the theoretical model. Data was collected from the cloud computing context, this included data from users and potential adopters of the cloud. Similar studies, such as (Opitz et al., 2012; Alharbi, 2012), suggest that cloud computing studies should target IT professionals. However, the scope of this study has been broadened to target an audience of IT professionals and end users.

\subsection{Research Method}

This current research designed a questionnaire as a means of obtaining responses from participants in Saudi Arabia with regard to their perception of cloud computing. The questionnaire consisted of eight constructs, as shown in Table 1. In addition, a Likert scale (1-7) was utilized for all questions, with anchors ranging from strongly disagree to strongly agree. Furthermore, the actual use questions utilized a yes/no scale. A number of other instruments were validated by the current literature, these have been utilized to suggest the items for each construct. In particular, the TAM scales were drawn from previous studies (Davis et al., 1989; Venkatesh and Davis, 2000) and tailored to fit the context at hand (cloud computing). To separate anxiety from both trust and perceived risk, anxiety scales were also adapted (Venkatesh, 2000).

Furthermore, perceived risk was considered in terms of the perceived security, privacy and reliability risks, as 
suggested by Marston et al. (2011) whereby in cloud technological risks, security, privacy and reliability are amongst the major concerns of $75 \%$ of IT managers (Marston et al., 2011). Similarly, Ratten (2012) argued that privacy and reliability are among several obstacles facing cloud computing. This argument is also supported by a recent study by (Rahimli, 2013). Perceived risk scales were also adapted from previous research (Benlian and Hess, 2011; Kim et al., 2008; Ratten, 2012). In addition, although trust is regarded as crucial for cloud computing, it depends largely on the consumer's self-assessment of the cloud service provider and their perception of the provider's reputation (Bamiah et al., 2014; Huang and Nicol, 2013). Due to the scope of this study, trust was considered in terms of trust in the cloud technology and trust in the cloud service provider. Trust of the cloud service provider can be measured in this context based on the perceptions of the provider's ability, benevolence and honesty (Aldiri et al., 2008). In particular, ability indicates the belief of the provider's skills; benevolence refers to the belief of the provider's personal interest; and, honesty denotes the belief of the provider's desire to keep their promises. Therefore, the trust scales were adapted to represent the same beliefs (Kim et al., 2008; Wu, 2011). Finally, the questionnaire was examined for validity, content and reliability through a panel of experts and statistical procedures. The questionnaire is shown in Table 1.

For data gathering purposes, a major event, held in Riyadh the capital of Saudi Arabia, was utilized in order to attract the event attendees to participate in the survey. The potential participants were then contacted via their official E-mail addresses that were obtained from the event registration records.

Table 1. Summary of measurement items

\begin{tabular}{|c|c|c|}
\hline \multicolumn{2}{|c|}{ Construct } & \multirow{2}{*}{$\begin{array}{l}\text { Item Measures } \\
\text { I would find cloud computing useful (Davis et al., 1989; Venkatesh and Davis, 2000). }\end{array}$} \\
\hline PU & PU1 & \\
\hline & PU2 & Using cloud computing would increase my efficiency (Davis et al., 1989; Du et al., 2013; Venkatesh and Davis, 2000). \\
\hline & PU3 & Using cloud computing increases my productivity (Davis et al., 1989; Du et al., 2013; Venkatesh and Davis, 2000). \\
\hline & PU4 & If I use cloud computing, I would accomplish my tasks more quickly \\
\hline & PU5 & I would find cloud computing effective for my tasks (Davis et al., 1989; Venkatesh and Davis, 2000). \\
\hline \multirow[t]{6}{*}{ PEOU } & PEOU1 & $\begin{array}{l}\text { Learning to operate cloud computing would be easy for me } \\
\text { (Davis } \text { et al., 1989; Du et al., 2013; Venkatesh and Davis, 2000). }\end{array}$ \\
\hline & PEOU2 & Using cloud computing would require less mental effort (Davis et al., 1989; Du et al., 2013; Venkatesh and Davis, 2000). \\
\hline & PEOU3 & $\begin{array}{l}\text { My interaction with cloud computing would be clear and understandable } \\
\text { (Davis } \text { et al., 1989; Du } \text { et al., 2013; Venkatesh and Davis, 2000). }\end{array}$ \\
\hline & PEOU4 & I would find cloud computing services flexible to interact with (Davis et al., 1989; Du et al., 2013; Venkatesh and Davis, 2000). \\
\hline & PEOU5 & It would be easy for me to become skillful at using cloud computing services (Davis et al., 1989; Venkatesh and Davis, 2000). \\
\hline & PEOU6 & In general, It is simple to use cloud computing (Davis et al., 1989; Du et al., 2013; Venkatesh and Davis, 2000). \\
\hline \multirow[t]{4}{*}{ ATT } & ATT1 & Using cloud computing is a good idea (Davis et al., 1989; Venkatesh and Davis, 2000). \\
\hline & ATT2 & I like the idea of using cloud computing (Davis et al., 1989; Venkatesh and Davis, 2000). \\
\hline & ATT3 & Using cloud computing is pleasant (Davis et al., 1989; Venkatesh and Davis, 2000). \\
\hline & ATT4 & I find using cloud computing enjoyable (Davis et al., 1989; Venkatesh and Davis, 2000). \\
\hline \multirow[t]{3}{*}{ BI } & BI1 & I will use cloud computing in the next 6 months (Davis et al., 1989; Venkatesh and Davis, 2000). \\
\hline & $\mathrm{BI} 2$ & I expect to be a regular user of cloud computing (Davis et al., 1989; Venkatesh and Davis, 2000). \\
\hline & $\mathrm{BI} 3$ & I intend to use cloud computing in the next 6 months (Davis et al., 1989; Venkatesh and Davis, 2000). \\
\hline \multirow[t]{4}{*}{ PR } & PR1 & I believe the confidentiality and security of my data are not guaranteed when using cloud computing (Benlian and Hess, 2011). \\
\hline & PR2 & I am concerned about privacy in cloud computing (Kim et al., 2008). \\
\hline & PR3 & I am concerned about cloud computing performance and reliability (Ratten, 2012). \\
\hline & PR4 & Overall, I consider the adoption of cloud computing to be risky (Benlian and Hess, 2011). \\
\hline \multirow[t]{4}{*}{ Trust } & TR1 & I trust the cloud because its vendors are competent and professional (Kim et al., 2008). \\
\hline & TR2 & The cloud vendor is one that keeps promises and commitments (Kim et al., 2008). \\
\hline & TR3 & I trust the cloud vendor because they keep my best interests in mind (Kim et al., 2008). \\
\hline & TR4 & Overall, the cloud is trustworthy (Wu, 2011). \\
\hline \multirow[t]{4}{*}{ ANX } & ANX1 & I feel apprehensive about using cloud computing (Nov and Ye, 2009; Venkatesh, 2000). \\
\hline & ANX2 & $\begin{array}{l}\text { It scares me to think that I could lose a lot of information using cloud computing by doing any mistake } \\
\text { (Nov and Ye, 2009; Venkatesh, 2000). }\end{array}$ \\
\hline & ANX3 & I hesitate to use cloud computing for fear of making mistakes I cannot correct (Nov and Ye, 2009; Venkatesh, 2000). \\
\hline & ANX4 & Cloud computing is somewhat intimidating to me (Nov and Ye, 2009; Venkatesh, 2000). \\
\hline \multirow[t]{2}{*}{$\mathrm{AU}$} & AU1 & I have used cloud services (Davis et al., 1989; Venkatesh and Davis, 2000). \\
\hline & AU2 & I am regularly using cloud services (Davis et al., 1989; Venkatesh and Davis, 2000). \\
\hline
\end{tabular}


The E-mail list revealed a diversity in the work environments, with the potential participants working for various government and business organizations. The E-mail message initially provided an introduction to the meaning of cloud computing, so as to ensure that the respondents were familiar with the cloud concepts and terminologies used. At the end of the E-mail message, a link was provided to an online questionnaire whereby the respondents could record their responses. In total, there were 966 responses from the 2,571 E-mails that were initially sent-this reflects a response rate of $37.5 \%$. Of these, 196 responses were disqualified because of incompleteness, invalidity, inconsistency or duplication, this resulted in a sample of 770 responses. Of this sample, it was assumed that all of the respondents were online users as they all used the Internet to fill in the questionnaire.

\subsection{Sample Characteristics}

The general demographics of the respondents can be seen in Table 2. Firstly, the sample size included a total of 770 respondents and, secondly, the table shows the different respondent demographics, including: Gender, background, age and education. In terms of gender, it can be seen that 250 women responded, which reflected $32.5 \%$ of the sample and $67.5 \%$ of the sample were men, which equates to 520 respondents. In terms of background, $65.5 \%$ of the sample had IT backgrounds (504 were IT specialists), where $35.4 \%$ of the sample had non-technological backgrounds (266 respondents). With regards to age, there were eight respondents that were aged less than 17 years old, this represented $1 \%$ of the sample and there were 234 respondents aged between 18 and 24 which represented $30.4 \%$ of the sample.

Table 2. Sample characteristics

\begin{tabular}{llcc}
\hline Respondent demographics & Frequency & Percent \\
\hline Number of respondents & 770 & 100.0 \\
Gender & Female & 250 & 32.5 \\
& Male & 520 & 67.5 \\
Background & Non-technology & 266 & 34.5 \\
& Computing and technology & 504 & 65.5 \\
Age & Less than 17 years & 8 & 1.0 \\
& $18-24$ & 234 & 30.4 \\
& $25-34$ & 450 & 58.4 \\
& $35-44$ & 60 & 7.8 \\
Education & 16 & 2.1 \\
& 45-54 & 2 & 0.3 \\
& 55 and above & 76 & 9.9 \\
& High school or under & 58 & 7.5 \\
& Two-year diploma & 496 & 64.4 \\
& Bachelor & 110 & 14.3 \\
& Master & 30 & 3.9 \\
\hline
\end{tabular}

It can also be seen that most of the sample were over the age of 25 years, with $450(58.4 \%)$ being aged between 25 and 34 years; $60(7.8 \%)$ were aged between 35 and 44 years; $16(2.1 \%)$ were aged between 45 and 54 years; and, finally, two $(0.3 \%)$ were aged either 55 years old or more. In terms of education, the sample included much variation with $76(9.9 \%)$ respondents being in high school education or under; $58(7.5 \%)$ of the respondents held a two-year diploma; 496 (64.4\%) held a bachelor degree; $110(14.3 \%)$ held a master degree; and, 30 (3.9\%) had a $\mathrm{PhD}$.

\subsection{Reliability and Validity of the Measurement Scale}

The following table, Table $\mathbf{3}$, summarizes the reliability and validity results, including: Cronbach's Alpha $(\alpha)$, Composite Reliability (CR) and Average Variance Extracted (AVE). It can be seen from the table that the research instrument was demonstrated to be internally consistent, as all of the values for Cronbach's Alpha were above the recommended level $(\alpha>0.7)$. Similarly, the CR and AVE for all factors were higher than 0.7 and 0.5, respectively (Hair et al., 1992). In addition, Table 4 shows the discriminate validity of the constructs. The instrument has also been shown to have adequate reliability measures, including convergent and discriminate validity.

\subsection{Model Testing Results}

By means of the Structural Equation Modeling (SEM), the theoretical model-fit was examined using several goodness-of-fit indices. Table 5 shows the model-fit indices, along with the acceptable fit interpretation. At a glance, it can be seen that the model-fit is statistically significant, with all indices satisfying the model-fit criteria. The chi-square/degree of freedom $(\chi 2 / \mathrm{df})$ results show a satisfactory level of 4.612, which is well below the threshold (5.00) that indicates good fit (Bagozzi and Yi, 1988). In addition, the Root Mean Square Error Approximation (RMSEA) reflected a good fit with 0.073 , which exceeds the acceptable levels (0.08) proposed by (Byrne, 2001). Furthermore, Byrne (2001) suggested that the smaller the Standardized Root Mean Square Residual (SRMR), the better the fit (Byrne, 2001). The estimate for SRMR was 0.074, this is indicative of a close fit. Similarly, the IFI $=0.927$, the NFI $=$ 0.911 , the CFI $=0,927$ and the TLI $=0.91$, all present no evidence of misfit. 
Table 3. Reliability results of the constructs

\begin{tabular}{|c|c|c|c|c|c|c|}
\hline Construct & Item & Loading & t-value & $\mathrm{A}$ & CR & AVE \\
\hline \multirow[t]{5}{*}{$\overline{\mathrm{PU}}$} & PU1 & 0.93 & 15.93 & 0.97 & 0.97 & 0.86 \\
\hline & PU2 & 0.95 & 15.03 & & & \\
\hline & PU3 & 0.94 & 15.44 & & & \\
\hline & PU4 & 0.93 & 16.13 & & & \\
\hline & PU5 & 0.87 & 17.94 & & & \\
\hline \multirow[t]{6}{*}{ PEOU } & PEOU1 & 0.86 & 17.29 & 0.95 & 0.95 & 0.76 \\
\hline & PEOU2 & 0.83 & 17.74 & & & \\
\hline & PEOU3 & 0.87 & 17.02 & & & \\
\hline & PEOU4 & 0.89 & 16.54 & & & \\
\hline & PEOU5 & 0.88 & 16.80 & & & \\
\hline & PEOU6 & 0.91 & 15.72 & & & \\
\hline \multirow[t]{4}{*}{ ATT } & ATT1 & 0.94 & 14.88 & 0.96 & 0.96 & 0.87 \\
\hline & ATT2 & 0.95 & 13.88 & & & \\
\hline & ATT3 & 0.93 & 16.13 & & & \\
\hline & ATT4 & 0.91 & 16.86 & & & \\
\hline \multirow[t]{3}{*}{ BI } & BI1 & 0.93 & 15.21 & 0.96 & 0.96 & 0.88 \\
\hline & $\mathrm{BI} 2$ & 0.93 & 18.26 & & & \\
\hline & $\mathrm{BI} 3$ & 0.95 & 15.64 & & & \\
\hline \multirow[t]{4}{*}{ PR } & PR1 & 0.85 & 18.16 & 0.88 & 0.92 & 0.75 \\
\hline & PR2 & 0.87 & 17.26 & & & \\
\hline & PR3 & 0.89 & 16.82 & & & \\
\hline & PR4 & 0.86 & 18.07 & & & \\
\hline \multirow[t]{4}{*}{ Trust } & TR1 & 0.82 & 16.20 & 0.89 & 0.93 & 0.77 \\
\hline & TR2 & 0.90 & 16.27 & & & \\
\hline & TR3 & 0.94 & 17.75 & & & \\
\hline & TR4 & 0.83 & 16.05 & & & \\
\hline \multirow[t]{4}{*}{ ANX } & ANX1 & 0.79 & 14.57 & 0.86 & 0.86 & 0.60 \\
\hline & ANX2 & 0.69 & 16.87 & & & \\
\hline & ANX3 & 0.80 & 14.05 & & & \\
\hline & ANX4 & 0.83 & 12.73 & & & \\
\hline \multirow[t]{2}{*}{$\mathrm{AU}$} & AU1 & 0.944 & 13.247 & 0.88 & 0.890 & 0.803 \\
\hline & AU2 & 0.845 & 12.831 & & & \\
\hline
\end{tabular}

Table 4. Discriminate validity of the constructs

\begin{tabular}{|c|c|c|c|c|c|c|c|c|}
\hline Latent variables & TR & ATT & PR & ANX & $\mathrm{AU}$ & $\mathrm{BI}$ & PEOU & PU \\
\hline TR & 0.875 & & & & & & & \\
\hline ATT & 0.734 & 0.933 & & & & & & \\
\hline PR & -0.241 & -0.361 & 0.867 & & & & & \\
\hline ANX & -0.295 & -0.338 & 0.175 & 0.777 & & & & \\
\hline $\mathrm{AU}$ & 0.727 & 0.711 & -0.274 & -0.305 & 0.896 & & & \\
\hline BI & 0.754 & 0.922 & -0.310 & -0.291 & 0.718 & 0.937 & & \\
\hline PEOU & 0.849 & 0.806 & -0.321 & -0.318 & 0.697 & 0.786 & 0.874 & \\
\hline PU & 0.714 & 0.894 & -0.348 & -0.335 & 0.695 & 0.853 & 0.822 & 0.925 \\
\hline
\end{tabular}

Table 5. Model-fit indices

\begin{tabular}{lll}
\hline Quality-of-fit measure & Structural model & Acceptable value \\
\hline Chi-square/degree of freedom $(\chi 2 / \mathrm{df})$ & 4.612 & $<5.00$ (Bagozzi and Yi, 1988) \\
Root Mean Square Error Approximation (RMSEA) & 0.073 & $\leq 0.08$ (Byrne, 2001) \\
Standardized RMR (SRMR) & 0.074 & the smaller the better (Byrne, 2001) \\
Incremental Fit Index (IFI) & 0.927 & $\geq 0.90$ (Schumacker and Lomax, 2010) \\
Normed Fit Index (NFI) & 0.911 & $\geq 0.90$ (Schumacker and Lomax, 2010) \\
Comparative Fit Index (CFI) & 0.927 & $\geq 0.90$ (Bagozzi and Yi, 1988) \\
Tucker Lewis Index (TLI) & 0.919 & $\geq 0.90$ (Byrne, 2001) \\
\hline
\end{tabular}




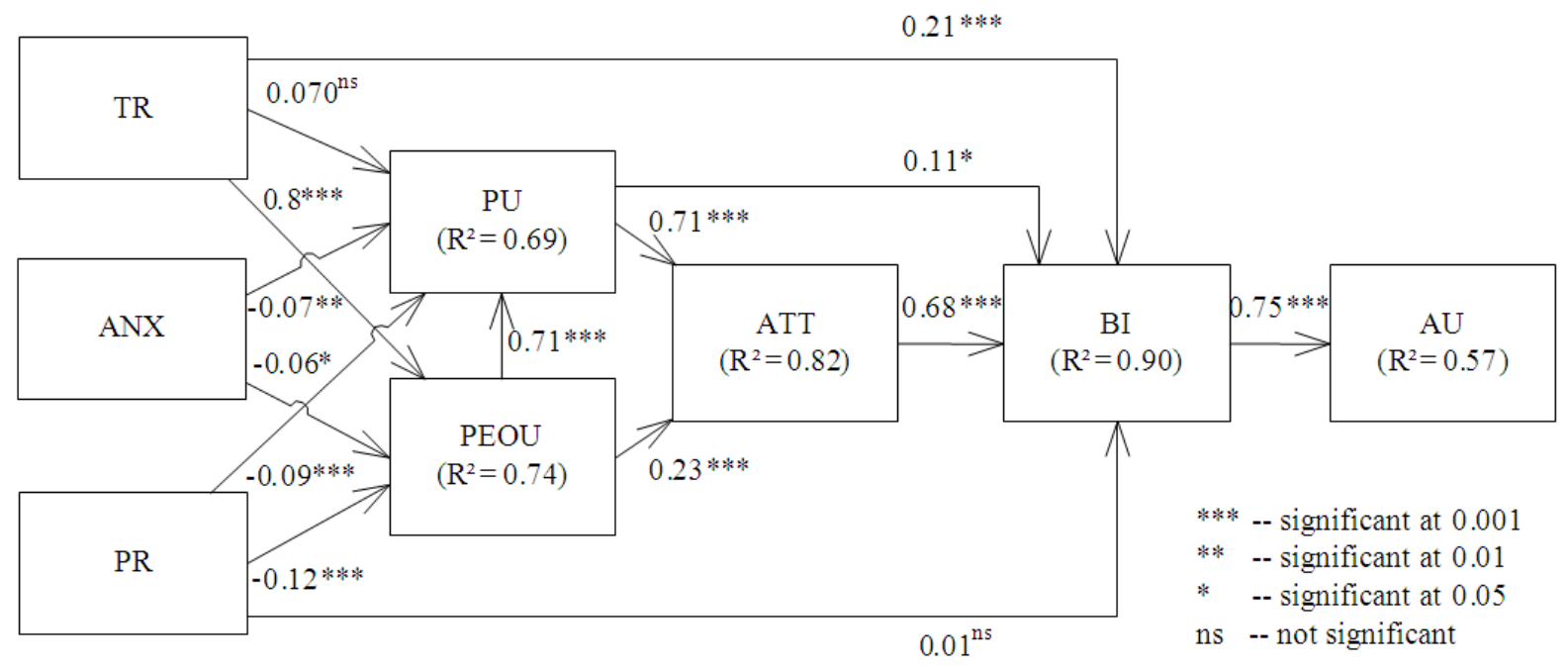

Fig. 3. SEM analysis of research model

The structural model examines five relationships that predict the variability in five main variables: PEOU, PU, ATT, BI and AU:

- First, the PEOU can be predicted by the three paths of: TR, ANX and PR; the path coefficients for TR, ANX and PR were $0.8(\mathrm{p}<0.1001),-0.06(\mathrm{p}<0.05)$ and $-0.12(\mathrm{p}<0.001)$, respectively. This indicated that TR had a significant positive effect on PEOU, while ANX and PR were found to have a significant negative effect on PEOU. The structural model explained approximately $74 \%$ of the variability in PEOU

- Secondly, the PU of the cloud can be predicted by three paths: PEOU, ANX and PR; the path coefficients for PEOU, ANX and PR were 0.71 $(\mathrm{p}<0.001), \quad-0.07 \quad(\mathrm{p}<0.01) \quad$ and $-0.09 \quad(\mathrm{p}<0.001)$, respectively. Both ANX and PR were found to have a significant negative effect on the PU of the cloud, while PEOU was found to have a significant positive effect on PU. However, the path coefficient for TR were found to be statistically insignificant, with $\beta=$ 0.07 and $p>0.05$. The model therefore accounted for approximately $69 \%$ of the variability in PU

- Thirdly, ATT was predicted by the following two paths: PU and PEOU, which were shown to be statistically significant; the path coefficients for PU and PEOU were $0.71(\mathrm{p}<0.001)$ and $0.23(0.001)$, respectively. With regard to this, the model explained approximately $82 \%$ of the variability in ATT
- Fourthly, in terms of the prediction of actual BI to use the cloud, the multiple regression equation suggested that the attitudes toward the cloud had a strong effect on the BI to use the cloud, as indicated by the path coefficient of $0.68(\mathrm{p}<0.001)$. The other path coefficients for TR and PU, which were 0.21 $(\mathrm{p}<0.001)$ and $0.11(\mathrm{p}<0.05)$, respectively, were less significant. The path coefficient for PR were found to be statistically insignificant, with $\beta=0.01$ and $p>0.05$; the structural model accounted for approximately $90 \%$ of the variability in BI to use the cloud

- Finally, AU can be predicted by the BI to use the cloud, as indicated by the path coefficient of 0.75 $(\mathrm{p}<0.001)$. The model therefore accounted for approximately $57 \%$ of the variability in AU of the cloud

The SEM analysis of the research model is presented, below in Fig. 3.

\section{DISCUSSION}

The following table, Table 6, shows the acceptance/rejection status of all of the research hypotheses as well as an assessment of the structural model. Firstly, the TAM has been shown to be a valid model for testing user acceptance of cloud computing in Saudi Arabia. This finding is in agreement with an earlier study (Alharbi, 2012). The table clearly illustrates that the hypotheses that were adapted from the original TAM (H7, H8, H9, H11, H12 and H14) have been accepted in the context of cloud computing. 
Mutlaq B. Alotaibi / Journal of Computer Science 10 (11): 2315.2329, 2014

Table 6. Summary of the model assessment

\begin{tabular}{|c|c|c|c|c|c|}
\hline $\mathrm{N}$ & Hypothesis Path & Path Coefficient $(\beta)$ & t-value & Significant & Comments \\
\hline$\overline{\mathrm{H} 1}$ & Trust $\rightarrow$ PU & $0.070^{\mathrm{ns}}$ & 1.360 & No & No significant effect \\
\hline $\mathrm{H} 2$ & Trust $\rightarrow$ PEOU & $0.804 * * *$ & 22.62 & Yes & Direct effect \\
\hline $\mathrm{H} 3$ & $\mathrm{ANX} \rightarrow \mathrm{PU}$ & $-0.074 * *$ & -2.972 & Yes & Direct effect \\
\hline $\mathrm{H} 4$ & ANX $\rightarrow$ PEOU & $-0.062 *$ & -2.455 & Yes & Direct effect \\
\hline H5 & $\mathrm{PR} \rightarrow \mathrm{PU}$ & $-0.093 * * *$ & -3.641 & Yes & Direct effect \\
\hline H6 & $\mathrm{PR} \rightarrow \mathrm{PEOU}$ & $-0.119 * * *$ & -4.684 & Yes & Direct effect \\
\hline $\mathrm{H} 7$ & $\mathrm{PU} \rightarrow \mathrm{ATT}$ & $0.709 * * *$ & 19.926 & Yes & Direct effect \\
\hline $\mathrm{H} 8$ & $\mathrm{PEOU} \rightarrow \mathrm{PU}$ & $0.709 * * *$ & 12.911 & Yes & Direct effect \\
\hline H9 & $\mathrm{PEOU} \rightarrow \mathrm{ATT}$ & $0.227 * * *$ & 6.644 & Yes & Direct effect \\
\hline $\mathrm{H} 10$ & Trust $\rightarrow$ BI & $0.209 * * *$ & 7.025 & Yes & Direct effect \\
\hline H11 & $\mathrm{PU} \rightarrow \mathrm{BI}$ & $0.112 *$ & 2.364 & Yes & Direct effect \\
\hline $\mathrm{H} 12$ & $\mathrm{ATT} \rightarrow \mathrm{BI}$ & $0.685 * * *$ & 14.074 & Yes & Direct effect \\
\hline $\mathrm{H} 13$ & $\mathrm{PR} \rightarrow \mathrm{BI}$ & $0.012^{\mathrm{ns}}$ & 0.586 & No & No significant effect \\
\hline H14 & $\mathrm{BI} \rightarrow \mathrm{AU}$ & $0.752 * * *$ & 24.103 & Yes & Direct effect \\
\hline
\end{tabular}

Secondly, the new external variables (TR, ANX and PR) were successfully integrated within the TAM. Trust has been shown to have a significant positive effect on PEOU and BI, but it has no significant effect on PU. Therefore, hypotheses $\mathrm{H} 2$ and $\mathrm{H} 10$ have been accepted and hypothesis H1 was rejected. This finding is in agreement with the argument presented by Udoh (2012) who found that trust explained $21 \%$ of variance in BI. Anxiety has been shown to have a significant negative effect on PEOU and PU; therefore, hypotheses H3 and $\mathrm{H} 4$ have been accepted. Perceived risk has been found to have a significant negative effect on PEOU and PU, but it appears to have no effect on BI; therefore, hypotheses H5 and H6 have been accepted and hypothesis H13 was rejected. The rejection of $\mathrm{H} 13$ contradicts the argument presented by (Chi et al., 2012) with regard to PR having a significant effect on BI.

\subsection{Implications of the Results}

The findings of this research are multifold. This investigation points to several new variables which also influence consumer attitudes and intentions to adopt the cloud, this is in addition to the core TAM variables. In this study, consumer trust in the cloud computing vendors was shown to be a key predictor of the acceptance of cloud computing. Therefore, it is recommended that Saudi companies are encouraged to leverage the cloud, particularly from companies with good reputations. This recommendation is not useful only for IT vendors but also for retail companies. In addition, although cloud computing risks are wellrecognized, Saudis exhibited risk-taking behaviors in the context of cloud computing, due to the absence of Etransactions that involved credit card payments. The nature of PR and its influence on consumer behaviors varies depending on several situations. One inherent PR situation is that individuals have a predisposition to avoid risk when making purchasing decisions (Dowling, 1986). With the context of cloud computing lacking any financial and e-payment risks, it is worth noting that respondents in this study exhibited risk-seeking behaviors. This PR finding contradicts with results that were revealed in other contexts, like E-Commerce, which involves purchasing and product selection decisions. Therefore, it can be said that PR does not affect the user's tendency to use the cloud.

This study provided valuable suggestions for cloud computing theory and practice. For researchers, it is important to consider the level at which cloud computing adoption was investigated. For example, a study of the cloud computing adoption by individuals could be measured at the application level (SaaS), while its counterpart, for organizations, could be measured at multiple levels (IaaS, PaaS and SaaS). Experience gained from this investigation suggests that cloud computing can be perceived at not only one layer ( $\mathrm{SaaS}$ ), by the end user, but at different layers by IT professionals. This investigation regularly observed that even IT professionals aggregated cloud computing into their SaaS, because not all of them had the chance to work with cloud computing at a level other than the application level. This argument is supported further by the respondents comments which indicated that cloud computing is viewed as an aggregate of SaaS products, such as cloud storage and applications. For IT professionals and managers, it is important to consider that the forthcoming adoption of the cloud is influenced by trust in cloud computing reliability, privacy and 
security. Saudi organizations will embrace the development of cloud computing, with particular focus on the cloud availability and the vendor's reputation. Therefore, it can be recommended that IT vendors should pay more attention to providing cloud computing services. On the other hand, Saudi IT authorities should propose data protection regulations for their cloud computing providers to ensure that security and privacy requirements are embedded within them.

During the survey, other important observations were also mentioned by the respondents. For example, one comment suggested that the use of SLA is critical to guaranteeing the availability and security of cloud services. Another comment raised important concerns which relate to the efficiency of cloud storage services, particularly for team work and collaboration. Another observation suggested that Saudis have become more aware of the potential of cloud computing. Therefore, it is expected that the tendency to accept cloud computing will increase in recent years, due to the maturity of cloud computing infrastructures and the increasing awareness of cloud computing potential in Saudi Arabia. For example, new trends in Saudi IT providers have been observed in terms of them offering cloud computing infrastructures and services not only to businesses but also to individuals. Recently, many Saudis have noticed widespread marketing campaigns, newspaper articles and training courses that are aimed at targeting cloud computing users. Therefore, it can be argued that the cloud hype has reached its peak of expectations, but time is still needed in order to raise awareness and develop knowledge, skills and infrastructures.

\subsection{Limitations and Future Research}

Although this study has presented results with statistical significance, this research is not without some limitations. Firstly, this research was conducted in Saudi Arabia, particularly in the main provinces and it may therefore not be a true representative of the entire population of the country. In order to generalize the findings, further investigations would be needed to examine user attitudes and intentions toward cloud computing in rural areas in Saudi Arabia, as this demographic represents about $20 \%$ of the population. Secondly, respondents with different backgrounds were targeted in this study; however, most of the responses were received from IT professionals, due to the increased awareness of cloud technology and applications among IT specialists, compared to end users. It is noteworthy that end users were rapidly using cloud technologies and applications, but sometimes clarification was needed to match the cloud concept with the product used, such as clarification that Dropbox is a product of a cloud-based storage service. Thirdly, it was also noticed that even IT professionals use clouds at an individual level, such as SaaS. Therefore, more in-depth analysis of using cloud computing by IT specialists is required, particularly in small and medium enterprises. Fourthly, by analyzing the respondents' notes, it was noticed that most of the comments by the respondents refer to the effect that friends and relatives had on them using the cloud. As the Saudi people rely heavily on social models to make decisions, further analysis would be needed on the effect of social influence in this area.

Finally, it can be said that all of the limitations encountered during this study have led to valuable suggestions for further research. Based on the experience gained from the research, it was noticed that Saudis appeared to place more trust in international key players of cloud computing, such as Google and Amazon, with regard to performance and reliability. Yet, they appeared to be concerned with privacy and therefore, ironically, preferred to use local providers of cloud computing. Therefore, a study on end user perceptions of cloud computing as provided by local, regional and international vendors merits further investigation.

\section{CONCLUSION}

Cloud computing represents a major shift in the computing field. A main objective of many organizations is to identify the elements that improve the adoption of cloud computing, so as to truly determine whether it is feasible for implementation. This study empirically examined various theoretical models and instruments in an attempt to understand the factors influencing cloud computing adoption. It proposed an extended TAM model tailored to fit the context of cloud computing, by integrating three external factors: Trust, anxiety and perceived risk.

This model has been demonstrated to be a true predictor of user intentions, toward the use of cloud computing, within the context of Saudi Arabia. Based on regression analysis, the results herein support the proposed model, as 12 out of the 14 hypotheses were confirmed. Experience gained from this investigation suggests that the adoption of cloud computing has a great potential for IT professionals and end users. In particular, trust in the cloud has been demonstrated to have a positive influence on PEOU, but not on PU. In addition, PR and ANX have also been shown to negatively influence PEOU and PU. Furthermore, TR, ATT and PU were found to be the key determinants of behavioral intentions to use the cloud, as 
PR was shown as having no effect on BI. This study has therefore provided user acceptance hints for cloud computing practitioners, while also opening up several new directions for further research.

\section{ACKNOWLEDGMENT}

I would like to acknowledge Al Imam Mohammad Ibn Saud Islamic University (IMSIU) for help, support and technical assistance.

\section{REFERENCES}

Al-Gahtani, S., 2001. The applicability of TAM outside North America: An empirical test in the United Kingdom. Inform. Resources Manage. J., 14: 37-46. DOI: 10.4018/irmj.2001070104

Al-Somali, S.A., R. Gholami and B. Clegg, 2009. An investigation into the acceptance of online banking in Saudi Arabia. Technovation, 29: 130-141. DOI: 10.1016/j.technovation.2008.07.004

Albaroodi, H., S. Manickam and P. Singh, 2014. Critical review of OpenStack security: Issues and weaknesses. J. Comput. Sci., 10: 23-33. DOI: 10.3844/jcssp.2014.23.33

Aldiri, K., D. Hobbs and R. Qahwaji, 2008. The human face of e-business: Engendering consumer initial trust through the use of images of sales personnel on e-commerce web sites. Int. J. E-Bus. Res., 4: 58-78. DOI: $10.4018 /$ jebr.2008100105

Alharbi, S.T., 2012. Users' acceptance of cloud computing in Saudi Arabia: An extension of technology acceptance model. Int. J. Cloud Applic. Comput., 2: 1-11. DOI: 10.4018/ijcac.2012040101

Atkinson, M. and C. Kydd, 1997. Individual characteristics associated with world wide web use: An empirical study of playfulness and motivation. ACM SIGMIS Database, 28: 53-62. DOI: 10.1145/264701.264705

Aymerich, F.M., G. Fenu and S. Surcis, 2008. An approach to a cloud computing network. Proceedings of the 1st International Conference on the Applications of Digital Information and Web Technologies, Aug. 4-6, IEEE Xplore Press, Ostrava, pp: 113-118. DOI: 10.1109/ICADIWT.2008.4664329

Bagozzi, R. and Y. Yi, 1988. On the evaluation of structural equation models. J. Acad. Market. Sci., 16: 74-94. DOI: 10.1007/BF02723327

Bamiah, M.A., S.N. Brohi, S. Chuprat and J.L.A. Manan, 2014. Trusted cloud computing framework for healthcare sector. J. Comput. Sci., 10: 240-250. DOI: 10.3844 jessp.2014.240.250
Barua, A., R. Chellappa and A.B. Whinston, 1995. Creating a collaboratory in cyberspace: Theoretical foundation and an implementation. J. Organ. Comput. Electronic Commerce, 5: 417-442.

Benlian, A. and T. Hess, 2011. Opportunities and risks of software-as-a-service: Findings from a survey of IT executives. Decision Support Syst., 52: 232-246. DOI: 10.1016/j.dss.2011.07.007

Biswas, D. and A. Biswas, 2004. The diagnostic role of signals in the context of perceived risks in online shopping: Do signals matter more on the web? J. Interactive Market., 18: 30-45. DOI: 10.1002/dir.20010

Bogataj, K. and A. Pucihar, 2012. Business model factors influencing cloud computing adoption. Proceeding of the 25th Bled eConference.

Buyya, R., S. Pandey and C. Vecchiola, 2009. Cloudbus Toolkit for Market-Oriented Cloud Computing. In: Cloud Computing, Springer, pp: 24-44.

Buyya, R., C.S. Yeo, S. Venugopal, J. Broberg and I. Brandic, 2009. Cloud computing and emerging IT platforms: Vision, hype and reality for delivering computing as the 5th utility. Future Generat. Comput. Syst., 25: 599-616. DOI: 10.1016/j.future.2008.12.001

Byrne, B.M., 2001. Structural equation modeling with AMOS, EQS and LISREL: Comparative approaches to testing for the factorial validity of a measuring instrument. Int. J. Test., 1: 55-86. DOI: 10.1207/S15327574IJT0101_4

Chi, H., H. Yeh and W.C. Hung, 2012. The moderating effect of subjective norm on cloud computing users' perceived risk and usage intention. Int. J. Market. Studies, 4: 95-102. DOI: 10.5539/ijms.v4n6p95

Coursaris, C., W. Van Osch and J. Sung, 2013. A" cloud lifestyle": The diffusion of cloud computing applications and the effect of demographic and lifestyle clusters. Proceeding of the Hawaii International Conference on System Sciences, Jan. 7-10, IEEE Xplore Press, Wailea, HI, USA, pp: 2803-2812. DOI: 10.1109/HICSS.2013.2

Davis, F.D., 1989. Perceived usefulness, perceived ease of use and user acceptance of information technology. MIS Q.

Davis, F.D., R.P. Bagozzi and P.R. Warshaw, 1989. User acceptance of computer technology: A comparison of two theoretical models. Manage. Sci., 35: 982-1003. DOI: 10.1287/mnsc.35.8.982 
Dillon, T., C. Wu and E. Chang, 2010. Cloud computing: Issues and challenges. Proceedings of the 24th IEEE International Conference on Advanced Information Networking and Applications, Apr. 20-23, IEEE Xplore Press, Perth, WA, pp: 27-33. DOI: 10.1109/AINA.2010.187

Dowling, G.R., 1986. Perceived risk: The concept and its measurement. Psychol. Market., 3: 193-210. DOI: 10.1002/mar.4220030307

Drennan, J., G. Sullivan and J. Previte, 2006. Privacy, risk perception and expert online behavior: An exploratory study of household end users. J. Organ. End User Comput., 18: 1-22. DOI: 10.4018/joeuc. 2006010101

Du, J., J. Lu, D. Wu, H. Li and J. Li, 2013. User acceptance of software as a service: Evidence from customers of China's leading e-commerce company, Alibaba. J. Syst. Software, 86: 2034-2044. DOI: 10.1016/j.jss.2013.03.012

Fishbein, M. and I. Ajzen, 1975. Belief, Attitude, Intention and Behavior: An Introduction to Theory and Research. 1st Edn., Addison-Wesley Pub. Co., Reading, ISBN-10: 0201020890, pp: 578.

Fishbein, M. and I. Ajzen, 2011. Predicting and Changing Behavior: The Reasoned Action Approach. 1st Edn., Taylor and Francis, New York, ISBN-10: 1136874739, pp: 538.

Fox, A., R. Griffith, A. Joseph, R. Katz and A. Konwinski et al., 2009. Above the clouds: A Berkeley view of cloud computing. University of California.

Gefen, D., 2004. TAM or just plain habit. In: Advanced Topics in End User Computing, Mahmood, M.A., Ed., Idea Group Inc, Hershey, Pa., ISBN-10: 1591402972.

Gefen, D. and D.W. Straub, 1997. Gender differences in the perception and use of e-mail: An extension to the technology acceptance model. MIS Q., 1: 389-400.

Hair, J.T., R.E. Anderson, R.L. Tatham and W.C. Black, 1992. Multivariate Data Analysis with Readings. 3rd Edn., NY, USA: Macmillan, New York.

Huang, J. and D.M. Nicol, 2013. Trust mechanisms for cloud computing. J. Cloud Comput.: Adv., Syst. Applic., 2: 9-9.

Khajeh-Hosseini, A., D. Greenwood and I. Sommerville, 2010. Cloud migration: A case study of migrating an enterprise it system to iaas. Proceedings of the IEEE 3rd International Conference on Cloud Computing, (CCC' 10).
Kim, D.J., D.L. Ferrin and H.R. Rao, 2008. A trust-based consumer decision-making model in electronic commerce: The role of trust, perceived risk and their antecedents. Decision Support Syst., 44: 544-564. DOI: 10.1016/j.dss.2007.07.001

King, W.R. and J. He, 2006. A meta-analysis of the technology acceptance model. Inform. Manage., 43: 740-755. DOI: 10.1016/j.im.2006.05.003

Lee, Y., K.A. Kozar and K.R.T. Larsen, 2003. The technology acceptance model: Past, present and future. Commun. Associat. Inform. Syst., 12: 752-780.

Liao, S., Y.P. Shao, H. Wang and A. Chen, 1999. The adoption of virtual banking: An empirical study. Int. J. Inform. Manage., 19: 63-74. DOI: 10.1016/S0268-4012(98)00047-4

Marston, S., Z. Li, S. Bandyopadhyay, J. Zhang and A. Ghalsasi, 2011. Cloud computing-the business perspective. Decision Support Syst., 51: 176-189. DOI: $10.1016 /$ j.dss.2010.12.006

Mehdi, N.A., A. Mamat, H. Ibrahim and S.K. Subramaniam, 2011. On the fly negotiation for urgent service level agreement on intercloud environment. J. Comput. Sci., 7: 1596-1604. DOI: 10.3844/jcssp.2011.1596.1604

Mohana, R.S. and P. Thangaraj, 2013. Machine learning approaches in improving service level agreementbased admission control for a software-as-a-service provider in cloud. J. Comput. Sci., 9: 1283-1294. DOI: $10.3844 /$ jcssp.2013.1283.1294

Moon, J.W. and Y.G. Kim, 2001. Extending the TAM for a world-wide-web context. Inform. Manage., 38: 217-230. DOI: 10.1016/S0378-7206(00)00061-6

Nov, O. and C. Ye, 2009. Resistance to change and the adoption of digital libraries: An integrative model. J. Am. Society Inform. Sci. Technol., 60: 1702-1708. DOI: $10.1002 /$ asi.21068

Nyoni, T. and R. Piderit, 2012. Enhancing trust in cloud computing. Proceedings of the 14th Annual Conference on World Wide Web Applications, Nov. 7-9.

Obeidat, M.A. and T. Turgay, 2012. Empirical analysis for the factors affecting the adoption of cloud computing initiatives by information technology executives. J. Manage. Res., 5: 152-178. DOI: 10.5296/jmr.v5i1.2764

Opitz, N., T.F. Langkau, N.H. Schmidt and L.M. Kolbe, 2012. Technology acceptance of cloud computing: Empirical evidence from German IT departments. Proceedings of the 45th Hawaii International Conference on System Science, Jan. 4-7, IEEE Xplore Press, Maui, HI, pp: 1593-1602. DOI: 10.1109/HICSS.2012.557 
Park, S. and S. Ryoo, 2012. An empirical investigation of end-users' switching toward cloud computing: A two factor theory perspective. Comput. Human Behavior, 29: 160-170. DOI: 10.1016/j.chb.2012.07.032

Pavlou, P.A., 2003. Consumer acceptance of electronic commerce: Integrating trust and risk with the technology acceptance model. Int. J. Electronic Commerce, 7: 101-134.

Pavlou, P.A. and L. Chai, 2002. What drives electronic commerce across cultures? Across-cultural empirical investigation of the theory of planned behavior. J. Electron. Commerce Res., 3: 240-253.

Rahimli, A., 2013. Factors influencing organization adoption decision on cloud computing. Int. J. Cloud Comput. Services Sci., 2: 141-147. DOI: 10.11591/closer.v2i2.2111

Ratten, V., 2012. Cloud computing services: Theoretical foundations of ethical and entrepreneurial adoption behaviour. Int. J. Cloud Applic. Comput., 2: 48-58. DOI: $10.4018 /$ ijcac.2012040105

Salkind, N.J. and T. Rainwater, 2000. Sm Exploring Research T/I/F. 4th Edn., Prentice Hall, Upper Saddle River, N.J., ISBN-10: 0130852988, pp: 85.

Samadi, M. and Y. Nejadi, 2009. A survey of the effect of consumers' perceived risk on purchase intention in E-Shopping. Bus. Intellig. J., 2: 261-271.

Schumacker, R. and R. Lomax, 2010. Model Fit. In: A Beginner's Guide to Structural Equation Modeling, Schumacker R.E. and R.G. Lomax (Eds.,), Routledge, ISBN-10: 1136968555, pp: 73-120.

Sotomayor, B., R.N.S. Montero, I.M. Llorente and I. Foster, 2009. Virtual infrastructure management in private and hybrid clouds. Internet Comput., IEEE, 13: 14-22. DOI: 10.1109/MIC.2009.119

Taylor, C.W. and D.S. Hunsinger, 2011. A study of student use of cloud computing applications. J. Inform. Technol. Manage., 22: 36-50.
Udoh, E., 2012. Technology acceptance model applied to the adoption of grid and cloud technology. Int. J. Grid High Performance Comput., 4: 1-20. DOI: 10.4018/jghpc.2012010101

Venkatesh, V., 2000. Determinants of perceived ease of use: Integrating control, intrinsic motivation and emotion into the technology acceptance model. Inform. Syst. Res., 11: 342-365. DOI: 10.1287/isre.11.4.342.11872

Venkatesh, V. and H. Bala, 2008. Technology acceptance model 3 and a research agenda on interventions. Decision Sci., 39: 273-315. DOI: 10.1111/j.1540-5915.2008.00192.x

Venkatesh, V. and F.D. Davis, 1996. A model of the antecedents of perceived ease of use: Development and test. Decision Sci., 27: 451-481. DOI: 10.1111/j.1540-5915.1996.tb01822.x

Venkatesh, V. and F.D. Davis, 2000. A theoretical extension of the technology acceptance model: Four longitudinal field studies. Manage. Sci., 46: 186204. DOI: $10.1287 / \mathrm{mnsc} .46 .2 .186 .11926$

Wu, C.F., 2013. Learning attitude and its effect on applying cloud computing service to IT education. Int. J. U- and E-Service, Sci. Technol., 6: 39-48.

Wu, W.W., 2011. Developing an explorative model for SaaS adoption. Expert Syst. Applic., 38: 1505715064. DOI: 10.1016/j.eswa.2011.05.039

Wu, W., L. Lan and Y. Lee, 2013. Factors hindering acceptance of using cloud services in university: A case study. Electron. Library, 31: 84-98. DOI: 10.1108/02640471311299155

Youseff, L., M. Butrico and D. Da Silva, 2008. Toward a unified ontology of cloud computing. Proceedings of the Grid Computing Environments Workshop, Nov. 12-16, IEEE Xplore Press, Austin, TX, pp: 1-10. DOI: 10.1109/GCE.2008.4738443 